\title{
Cardioprotective effects of bilberry extract on ischemia-reperfusion-induced injury in isolated rat heart Lovro Žiberna*1, Mojca Lunder ${ }^{1}$, Špela Može ${ }^{2}$, Andreja Vanzo ${ }^{3}$ and Gorazd Drevenšek ${ }^{1}$
}

\author{
Address: ${ }^{1}$ Institute of Pharmacology and Experimental Toxicology, Faculty of Medicine, University of Ljubljana, 1000 Ljubljana, Slovenia, \\ ${ }^{2}$ Department of Food Science and Technology, Biotechnical Faculty, University of Ljubljana, 1000 Ljubljana, Slovenia and ${ }^{3}$ Department of \\ Oenology, Agricultural Institute of Slovenia, 1000 Ljubljana, Slovenia \\ Email: Lovro Žiberna* - lovro.ziberna@mf.uni-lj.si \\ * Corresponding author
}

\author{
from I5th Scientific Symposium of the Austrian Pharmacological Society (APHAR) Joint meeting with the Hungarian Society of Experimental and Clinical \\ Pharmacology (MFT) and the Slovenian Pharmacological Society (SDF) \\ Graz, Austria. 19-21 November 2009 \\ Published: 12 November 2009 \\ BMC Pharmacology 2009, 9(Suppl 2):A55 doi:10.1 I86/I47|-22। 0-9-S2-A55
}

This abstract is available from: http://www.biomedcentral.com/I47I-22/0/9/S2/A55

(c) 2009 Žiberna et al; licensee BioMed Central Ltd.

\section{Background}

Bilberries (Vaccinium myrtillus L.) are recognized as a good source of flavonoids, especially anthocyanins, which have strong antioxidative activity. Therefore, they may have a strong potential as cardioprotective agents in ischemicreperfusion injury.

\section{Methods}

Anthocyanins from the prepared bilberry extract were analyzed using the HPLC-DAD system and were expressed as a standard of cyanidine-3-glucoside (mg/L). Experiments were carried out on the isolated hearts from Wistar rats of both sexes according to the Langendorff method. Postischemic myocardial injuries during reperfusion were determined by changes in coronary flow rate, lactate dehydrogenase (LDH) release rate, electrocardiogram analysis, incidence and duration of arrhythmias.

\section{Results}

Bilberry extract $(0.01-5 \mathrm{mg} / \mathrm{L})$ increased coronary flow and decreased LDH release rate during reperfusion. Coronary flow was increased up to 2.5 -fold $(\mathrm{p}<0.001)$ at 0.1 $\mathrm{mg} / \mathrm{L}$ and up to 2.0 -fold ( $\mathrm{p}<0.01)$ at $1 \mathrm{mg} / \mathrm{L}$ compared to the control values. The LDH release rates were decreased 3.7 -fold ( $\mathrm{p}<0.001)$ at $0.1 \mathrm{mg} / \mathrm{L}$ and 6.7 -fold $(\mathrm{p}<0.001)$ at $1 \mathrm{mg} / \mathrm{L}$ compared to the control. Furthermore, the application of bilberry extract was also effective in the prevention of arrhythmias. The duration of arrhythmias was maximally shortened at $0.1 \mathrm{mg} / \mathrm{L}$ to $3.2 \pm 0.2 \%$ (p < $0.001)$ and at $1 \mathrm{mg} / \mathrm{L}$ group to $4.4 \pm 0.3 \%(\mathrm{p}<0.001)$ of the control value from the untreated group. However, the bilberry extract had no significant effect on heart rate and on left ventricular developed pressure.

\section{Conclusion}

Our results show that bilberry extract has anti-ischemic and anti-arrhythmic activity on ischemia-reperfusioninduced injury in isolated rat hearts. 